Çiğdem SONMEZ1

A. Özge ŞIMŞEK SOYSAL2

Amir Hasan TAGHILOOFAR ${ }^{1}$

Emine BAYRAM ${ }^{1}$

Hakan COŞKUNOL ${ }^{3}$

${ }^{1}$ Ege Üniversitesi, Ziraat Fakültesi, Tarla Bitkileri Bölümü, 35100, Izmir / Türkiye

2 Ordu Üniversitesi, Ziraat Fakültesi, Tarla Bitkileri Bölümü, 52200, Ordu /Türkiye

3 Ege Üniversitesi, Tıp Fakültesi, Ruh Sağlığı ve Hastalıkları Anabilim Dalı, 35100, Muğla /Türkiye sorumlu yazar: cigdem.sonmez@ege.edu.tr

Anahtar Sözcükler:

Hodan, Borago officinalis L., verim, kalite

Key Words:

Borage, Borago officinalis L., yield, quality

\section{Menemen Ekolojik Koşullarında Borago officinalis L. (Hodan) Bitkisinde Farklı Sıra Arası Mesafelerinin Bazı Verim ve Kalite Özelliklerine Etkileri}

\author{
The Effect of Different Row Spacings on Some Yield and \\ Quality Characters in Borago officinalis L. (Borage) in \\ Ecological Conditions of Menemen
}

Alınış (Received): 03.07.2017～Kabul tarihi (Accepted): 03.08.2017

\section{ÖZET}

u ç̧alışma EÜ Ziraat Fakültesi Menemen Araştırma ve Üretim Çiftliğinde organik Düretim alanında 2014-2015 ve 2015-2016 yıllarında gerçekleştirilmiştir. İki yıl süreyle yürütülen bu araştırmada Borago officinalis $L$. bitkisinin bazı verim ve kalite özellikleri üzerine farklı sıra arası mesafelerinin $(30 \mathrm{~cm}, 40 \mathrm{~cm}, 50 \mathrm{~cm}$ ve $60 \mathrm{~cm})$ etkileri araştırılmıştır. Illk ve ikinci deneme yıllarında sırasıyla bitki boyu 58.16-77.0 $\mathrm{cm}, 65.86-75.93 \mathrm{~cm}$; 1000 tane ağırığı 16.3-17.0 g, 15.0-16.4 g; dal sayısı 5.96-7.46 adet/bitki, 6.55-8.10 adet/bitki; salkım sayısı 27.40-41.86 adet/bitki, 31.50-33.85 adet/bitki; tane verimi $44.38-76.39 \mathrm{~kg} / \mathrm{da}, 41.67-79.72 \mathrm{~kg} / \mathrm{da}$ arasında değişmiştir. Her iki deneme yılında da sıra arası mesafeleri arttıkça 1000 tane ağırığı dışındaki değerlerin artış gösterdiği belirlenmiştir. Araştırmada sabit yağ oranları ilk yıl \%29.96-34.04, ikinci yıl \%30.13-33.67 aralığında değişmiştir. Sıra arası mesafeleri arttıkça sabit yağ oranlarında bir azalma gözlenmiştir. Yağ bileşimleri incelendiğinde, yıllar ortalaması olarak palmitik asit \%13.10-13.31, stearik asit \%3.78-4.07, oleik asit \%20.26-20.74, linoleik asit \%36.40-37.54, Y- linolenik asit $\% 18.20-18.71$, eikosenoik asit \%4.09-4.25 ve erüsik asit \%2.36-2.60 olarak saptanmıştır. Sonuçta Borago officinalis bitkisinde kabul edilebilir tane verimi ile birlikte yüksek düzeyde yağ içeriği elde edilebilmesi bakımından $50 \mathrm{~cm}$ sıra arası mesafesinin uygulanması gerektiğini söylemek mümkündür.

\section{ABSTRACT}

7

his study was carried out in the field of organic production at the Menemen research and production farm of Ege University in 2014-2015 and 2015-2016. In this research that conducted for two years, were investigated of the effects of four different row spacings $(30 \mathrm{~cm}, 40 \mathrm{~cm}, 50 \mathrm{~cm}$ and $60 \mathrm{~cm}$ ) on some yield and quality characteristics of Borago officinalis L.. In the first and second years of the experiment, the plant height, 1000 seed weight, number of branches, number of inflorescences and seed yield were changed between $58.16-77.00 \mathrm{~cm}, 65.86-$ $75.93 \mathrm{~cm}$; 16.3- $17.0 \mathrm{~g}, 15.0-16.4 \mathrm{~g}$; 5.96- 7.46 per plant, 6.55- 8.10 per plant; 27.4041.86 per plant, 31.50- 33.85 per plant; $44.38-76.39 \mathrm{~kg} / \mathrm{da}, 41.67-79.72 \mathrm{~kg} / \mathrm{da}$ respectively. In both experiment years, in investigated parameters were observed increase except 1000 seeds yields in these values with the increases of the distance between rows. Further oil ratio was determined in the range of $\% 29.96$ 34.04 and \% 30.13- 33.67 at the first and second years of experiment respectively. The result of the experiment indicated that there was a decrease in oil ratio as increases of the distance between rows. Analysis of fatty acids oil of Borago officinalis $L$. indicated that the ratio of palmitic acid, stearic acid, oleic acid, linoleic acid, $Y$-linolenic acid, eicosenoic acid and erucic acid were \%13.10-13.31, \%3.784.07, \%20.26-20.74, \%36.40-37.54, \%18.20-18.71, \%4.09-4.25 and \%2.36-2.60 in averages of years respectively. In result, it is possible to say that $50 \mathrm{~cm}$ distance between rows must be applied in order to obtain an acceptable high level of oil content with seed yield in Borago officinalis $L$. 


\section{GíRiş}

Borago officinalis L. (Hodan) Boraginaceae familyasına dahil $30-60 \mathrm{~cm}$ yüksekliğinde, sert tüylü, açık mavi çiçekli, bir yıllık otsu bir bitki olup yaprakları sebze olarak kullanılmaktadır (Baytop, 1999). Hodan (Borago officinalis L.) Akdeniz bölgesine özgü olarak geleneksel tıp ve mutfağında kullanılan bir bitkidir. Bir mutfak bitkisi olarak, borago yaprakları sebze olarak, turşu, salata ve buzlu içeceklerde tüketilmektedir. Çiçekleri salatalar için yenilebilir bir dekorasyon malzemesi olarak kullanılmaktadır. Birçok Akdeniz ülkesinde bitkinin yenilebilir kısmı, besleyici değeri yüksek bazal yaprak sapıdır (Medrano ve ark., 1992). Çiçekleri salkım halinde aşağıya doğru sarkmaktadır. Bu bitkinin yetiştiriciliğinde, kendine uyuşmaz bir bitki olması nedeni ile döllenmesinde böcekler bir polen taşıyıcısı olarak önemli rol oynamakta olup hektar başına en az iki kovan bal arısı olması dikkate alınmalıdır (El Hafid ve ark., 2002). Yurdumuzda Batı ve Kuzey Anadolu'da yayılış göstermektedir (Zeybek ve Zeybek, 1994). Boraginaceae familyası $Y$-linolenik asit (GLA)'in en önemli kaynaklarından biri olarak bilinmektedir (Samani ve ark., 2014). Bu bitkinin de özellikle tohumları Y- linolenik asit (C18:3) kaynağı olarak önemlidir. Ylinolenik asit (GLA) başlıca doymamış yağ asitlerinden birisi olan linoleik asidin 6-doymamış metobolitidir ve diğer en önemli kaynağı gece sefası (Oenothera biennis L.) bitkisidir (Şekeroğlu, 2003). GLA üretimi nispeten iyi bilinmektedir ve bu yağ asidi genellikle gece sefası (Oenothera biennis), hodan (Borago officinalis) ve siyahfrenk üzümü (Ribes nigrum) gibi bitki kaynaklarından elde edilmektedir (Gunstone, 1998).

Borago officinalis L. bitkisi yüksek oranda $Y$ linolenik asit içermesinden dolayı Neurodermitis hastalığında kullanılmaktadır (Cergel ve ark. 2006). GLA takviyeleri romatoid artrit ve atopik egzema gibi çeşitli hastalıklar ve inflamatuar koşullar üzerinde etkilidir. Klinik testler GLA'nın sağlık ve tıbbi yararları olduğunu doğrulamaktadır. Balık yağı ve Borago tohumu yağı ile yaşlı osteoporotik kadınlar üzerinde yapılan bir çalışmada kemik yoğunluğunda düzelme görülmüştür. Diyabetiklerde sinir fonksiyon bozukluğu için yapılan $Y$ linolenik asit (GLA) çalışmaları, GLA'nın diyabetik nöropatinin tedavisinde olumlu sonuçlar vaat ettiğini göstermiştir. Ancak tüm bu tıbbi koşullardaki Borago officinalis kullanımı ile ilgili bilgiler sınırıdır (Bone ve Mills, 2013). Borago bitkisini $\mathrm{Cd}$ akümülatörü olarak sınıflandıran çalışmalar mevcuttur. Cergel ve ark. (2006) tarafından ağır metal olarak bilinen Cadmium içeriğinin tohumlarda sınır değer olarak kabul edilen $0.20 \mathrm{mg} / \mathrm{kg}$ KM miktarını çoğu kez aşabildiği ifade edilmekte ve Borago bitkisine yönelik seleksiyonlarda Cd içeriği özelliğinin dikkate alınması gerektiği vurgulanmaktadır.
Tohumdan elde edilen değerli bir yağ asidi olan $Y$ linolenik asidin (GLA) potansiyel pazarı nedeniyle tarımsal üretimde gitgide bu bitkinin yetiştiriciliğine artan bir ilgi söz konusu olmuştur. Ülkemizde bu bitkinin kalitesine yönelik bazı çalışmalar yapılmış ancak yetiştirme tekniğine yönelik bir çalışmaya rastlanmamıştır. Bu nedenle, yapılan araştırmada Menemen ekolojik koşullarında Borago officinalis L. (Hodan) bitkisinin farklı sıra arası mesafeleri uygulaması ile verim ve kalite özelliklerindeki değişim incelenmiştir.

\section{MATERYAL ve YÖNTEM}

Araştırma Ege Üniversitesi Ziraat Fakültesi Menemen Araştırma, Uygulama ve Üretim Çiftliğinde 2014-2015 ve 2015-2016 yıllarında organik sertifikalı üretim yapılan alanda iki yıl süreyle yürütülmüştür. Araştırma Tesadüf Blokları Deneme Desenine göre üç tekrarlamalı olarak kurulmuş̧tur. Denemede dört farklı sıra arası mesafesi $(30 \mathrm{~cm}, 40 \mathrm{~cm}, 50 \mathrm{~cm}$ ve $60 \mathrm{~cm})$ uygulanmıştır. Borago officinalis L. tohumları tarlaya ilk yıl 07.11.2014, ikinci yıl 04.11.2015 tarihlerinde dekara $800 \mathrm{~g}$ tohumluk gelecek şekilde ekilmiştir. Denemede Almanya kökenli Borago officinalis $\mathrm{L}$. tohumları kullanılmıştır. Her sıraya ekilecek tohumluk miktarı ayrı ayrı hesaplanarak tartılmış ve ekim gerçekleştirilmiştir. Her parselde dört sıra olacak şekilde parsel boyutları $30 \mathrm{~cm}$ sıra arasında $1.2 \mathrm{~m} \times 4.0 \mathrm{~m}=4.8$ $\mathrm{m}^{2}, 40 \mathrm{~cm}$ sıra arasında $1.6 \mathrm{~m} \times 4.0 \mathrm{~m}=6.4 \mathrm{~m}^{2}, 50 \mathrm{~cm}$ sıra arasında $2.0 \times 4 \mathrm{~m}=8 \mathrm{~m}^{2}$ ve $60 \mathrm{~cm}$ sira arasında $2.4 \mathrm{~m} \mathrm{x}$ $4.0=9.6 \mathrm{~m}^{2}$ olarak belirlenmiştir. Hasatta her parselin başından ve sonundan $0.5 \mathrm{~m}$ kenar tesiri olarak bırakılarak ortadaki iki sıra hasat edilmiştir. Deneme bitkilerinin hasat işlemi ilk yıl 14.05.2015, ikinci yıl 10.05.2016 tarihlerinde gerçekleştirilmiştir.

Araştırmanın yürütüldügü deneme alanının toprak özellikleri kumlu-killi yapıda, pH değeri 7.65 olup hafif alkali sınıfındadır. Organik sertifikalı üretim alanına iki yılda bir sonbaharda dekara 2 ton olacak şekilde yanmış ahır gübresi uygulaması yapılmaktadır.

Denemede bitki boyu (cm), 1000 tane ağırlığı (g), dal sayısı (adet/bitki), salkım sayısı (adet/ bitki), tane verimi (kg/da), sabit yağ oranı (\%) ve bileşimi (\%) belirlenmiştir. Sabit yağ oranı (\%) Soxhlet apareyinde n-hekzan ekstraksiyonu yöntemi ile belirlenmiştir.

Borago tohumlarında ekstraksiyonu yapılmış olan sabit yağların kompozisyonlarının belirlenmesi metilasyon işlemi yapıldıktan sonra FAME (Fatty Acid Methyl Esters) IUPAC No:2.301'e göre yapılmıştır (IUPAC, 1979).

$\mathrm{Bu}$ analizde yağ asitleri kompozisyonu, Hewlett Packard $6890 \mathrm{~N}$ modelli gaz kromatografisi cihazında (Agilent, Polo Alto, CA) ile 60 metre uzunlukta "Supelco 2380" marka kapiler klon 
$(60 \mathrm{~m} \times 0.25 \mathrm{~mm}$ i.d., $0.20 \mu \mathrm{m}$ film kalınlığı; Supelco, Bellefonte, PA, ABD) ve alev iyonlaştırma detektörü (FID) kullanılarak yapılmıştır. Yağ asitlerinin fraksiyon tayininde çıkan pikler 37 FAME yağ asidini içeren standart karışımından (Supelco ${ }^{\mathrm{TM}}$ 37 Component FAME mix, Supelco, Bellefonte,
PA, ABD) yararlanılarak tanımlanmıştır. Analiz sırasında çıkan pikler, standarttan yararlanarak pikin zaman ve alan hesaplaması ile fraksiyonların tespit edilmiş ve sonuçlar \% yağ asidi olarak verilmiştir. Gaz kromatogafisinin çalışma koşulları aşağıda belirtildiği gibi programlanmıştır:

$\begin{array}{llll}\text { Fırın sıcaklığı } & : 165^{\circ} \mathrm{C} 35 \text { dak., } 5^{\circ} \mathrm{C} / \mathrm{dk} 195^{\circ} \mathrm{C}, 195^{\circ} \mathrm{C} 15 \mathrm{dk} & \\ \text { İnlet sıcaklığı } & : 220^{\circ} \mathrm{C} & \text { Detektör sıcaklığı } & : 220^{\circ} \mathrm{C} \\ \text { Taşıyıcı gaz } & : \text { Helyum } & \text { Gaz akış hızı } & : 1.1 \mathrm{ml} / \mathrm{dk} \\ \text { Basınç } & : 30.49 \mathrm{psi} & \text { Enjeksiyon miktarı }: 1 \mu \mathrm{l}\end{array}$

Verim ve bazı verim özellikleri için her bir yetiştirme döneminde elde edilen veriler Tesadüf Blokları Deneme Desenine göre varyans analizine tabi tutulmuştur. Varyans analizleri TOTEMSTAT paket programı kullanılarak yapılmıştır (Açıkgöz ve ark, 2004). Sıra arası mesafesinin etkisi bakımından istatistiksel olarak önemli farklılıklar bulunan özelliklerde ortalamalar LSD testine göre gruplandırılmıştır.

\section{ARAŞTIRMA BULGULARI ve TARTIŞMA}

Borago officinalis ile yapılan çalışmaya ait Çizelge 1 incelendiğinde, ilk yıl bitki boyu ortalamaları en düşük $58.16 \mathrm{~cm}$, en yüksek $77.0 \mathrm{~cm}$ olarak belirlenmiştir. İkinci yıl ise en düşük bitki boyu
$65.86 \mathrm{~cm}$, en yüksek bitki boyu $75.93 \mathrm{~cm}$ olmuştur. Her iki yılda da sıra arası mesafe arttıkça bitki boylarında artış gözlenmiştir. Bitki boyuna paralel olarak genellikle sıra arası mesafesi arttıkça bitkilerin daha iyi ve gür geliştiği dikkati çekmiştir. 2015 yılında bitki boyu bakımından istatistiksel açıdan \%1 düzeyinde farklılıklar saptanmış ve $50 \mathrm{~cm}$ ve $60 \mathrm{~cm}$ sıra arası mesafelerdeki bitki boyu değerleri ilk grupta yer almıştır. Hendawy ve El-Gengaihi (2010) farklı azot ve fosfor kaynaklarının Borago officinalis üzerine etkisini inceledikleri çalışmalarında bitki boyunu 75-111 cm aralığında, Berti ve ark. (2010) ise Şili'de yaptıkları bir çalışmada farklı azot dozlarına göre 48-58 cm olarak bildirmişlerdir.

Çizelge 1. Borago officinalis L.'de Farklı Sıra Arası Mesafelerinin Bazı Verim Özelliklerine Etkileri Table 1. The Effect of Different Row Spacings on Some Yield Characters in Borago officinalis L.

\begin{tabular}{|c|c|c|c|c|c|}
\hline \multicolumn{6}{|c|}{ 2014-2015 } \\
\hline $\begin{array}{c}\text { Sıra Arası } \\
\text { Mesafe }(\mathrm{cm})\end{array}$ & $\begin{array}{c}\text { Bitki Boyu } \\
(\mathrm{cm})\end{array}$ & $\begin{array}{l}1000 \text { Tane } \\
\text { Ağırlığı (g) }\end{array}$ & $\begin{array}{c}\text { Dal Sayısı } \\
\text { (adet/bitki) }\end{array}$ & $\begin{array}{l}\text { Salkım Sayısı } \\
\text { (adet/bitki) }\end{array}$ & $\begin{array}{c}\text { Tane Verimi } \\
(\mathrm{kg} / \mathrm{da})\end{array}$ \\
\hline 30 & 58.16 b & 16.9 & 5.96 & 27.70 & 44.45 b \\
\hline 40 & 59.03 b & 16.6 & 6.73 & 27.40 & $44.38 \quad \mathbf{b}$ \\
\hline 50 & $77.00 \mathbf{a}$ & 17.0 & 7.46 & 31.43 & $72.00 \mathbf{a}$ \\
\hline 60 & 73.83 a & 16.3 & 7.16 & 41.86 & $76.39 \mathbf{a}$ \\
\hline Genel Ort & 67.01 & 16.7 & 6.83 & 32.10 & 59.30 \\
\hline LSD & 8.441 & öd & öd & öd & 7.63 \\
\hline \multicolumn{6}{|c|}{ 2015-2016 } \\
\hline $\begin{array}{c}\text { Sıra Arası } \\
\text { Mesafe }(\mathrm{cm})\end{array}$ & $\begin{array}{c}\text { Bitki Boyu } \\
(\mathrm{cm})\end{array}$ & $\begin{array}{l}1000 \text { Tane } \\
\text { Ağırlığı (g) }\end{array}$ & $\begin{array}{c}\text { Dal Sayısı } \\
\text { (adet/bitki) }\end{array}$ & $\begin{array}{l}\text { Salkım Sayısı } \\
\text { (adet/bitki) }\end{array}$ & $\begin{array}{c}\text { Tane Verimi } \\
(\mathrm{kg} / \mathrm{da})\end{array}$ \\
\hline 30 & 65.86 & 15.6 & 6.80 & 31.50 & $41.67 \mathbf{b}$ \\
\hline 40 & 69.10 & 15.4 & 6.55 & 32.03 & $46.25 \mathrm{~b}$ \\
\hline 50 & 75.16 & 16.4 & 8.10 & 31.56 & $73.33 \mathbf{a}$ \\
\hline 60 & 75.93 & 15.0 & 7.76 & 33.85 & $79.72 \mathbf{a}$ \\
\hline Genel Ort & 71.52 & 15.6 & 7.30 & 32.23 & 60.24 \\
\hline LSD & öd & öd & öd & öd & 11.11 \\
\hline \multicolumn{6}{|c|}{ Yıllar Ortalaması } \\
\hline $\begin{array}{c}\text { Sıra Arası } \\
\text { Mesafe }(\mathrm{cm})\end{array}$ & $\begin{array}{c}\text { Bitki Boyu } \\
(\mathrm{cm})\end{array}$ & $\begin{array}{l}1000 \text { tane } \\
\text { ağırlığı (g) }\end{array}$ & $\begin{array}{c}\text { Dal Sayısı } \\
\text { (adet/bitki) }\end{array}$ & $\begin{array}{c}\text { Salkım Sayısı } \\
\text { (adet/bitki) }\end{array}$ & $\begin{array}{c}\text { Tane Verimi } \\
(\mathrm{kg} / \mathrm{da})\end{array}$ \\
\hline 30 & $62.02 \mathrm{~b}$ & 16.3 & 6.38 & 29.60 & $43.06 \mathrm{c}$ \\
\hline 40 & 64.06 b & 16.0 & 6.64 & 29.72 & 45.32 \\
\hline 50 & 76.08 a & 16.8 & 7.78 & 31.50 & $72.50 \quad$ b \\
\hline 60 & 74.88 a & 15.7 & 7.47 & 37.86 & $78.05 \quad \mathbf{a}$ \\
\hline Genel Ort & 69.26 & 16.2 & 7.07 & 32.17 & 59.73 \\
\hline LSD & 8.07 & öd & öd & öd & 5.55 \\
\hline
\end{tabular}


Bizim bulduğumuz sonuçlar (min. $58.16 \mathrm{~cm}$-mak. $77.0 \mathrm{~cm}$ ) Berti ve ark. (2010)'nın elde ettikleri maksimum değer ile Hendawy ve El-Gengaihi (2010)'un bildirdikleri minimum değer arasında yer almaktadır. İkinci deneme yılında, dar sıra aralığında $(30 \mathrm{~cm})$ elde edilen bitki boyunun geniş sıra aralıklarına (50 ve $60 \mathrm{~cm}$ ) göre nispeten kısa olmasına karşın (yaklaşık $10 \mathrm{~cm}$ ) önemsiz bir fark olarak görünmesinin olaslıkla deneme hatasının yüksekliğinden ileri geldiği söylenebilir.

Deneme yıllarına ait ortalamalar birleştirildiğinde bitki boyu bakımından farklılık istatistiksel olarak önemli bulunmuş olup, $50 \mathrm{~cm}$ ve $60 \mathrm{~cm}$ sıra arası mesafelerinde en yüksek değerler (sırasıyla $76.08 \mathrm{~cm}$ ve $74.88 \mathrm{~cm}$ ) elde edilmiştir. Kolza çeşitleri ile yapılan bir araştırmada da en yüksek bitki boyu değeri en geniş sıra arasından $(50 \mathrm{~cm})$ elde edilmiştir (Öztürk, 2000).

Borago officinalisile yaptığımız denemede 1000 tane ağırlığına ait değerler incelendiğinde; ilk yıl ortalama $16.7 \mathrm{~g}$, ikinci yıl ortalama $15.6 \mathrm{~g}$ olarak belirlenmiştir (Çizelge 1). Ayrıca her iki yılda da elde edilen sonuçlar istatistiksel açıdan değerlendirildiğinde, sıra arası mesafeleri arasındaki farklıı̆ın önemsiz olduğu saptanmıştır. Bununla birlikte, sayısal olarak da ikinci yıl 1000 tane ağırlığı değerleri ilk yıla göre biraz daha düşük bulunmuştur. De Haro ve ark. (2002) İspanya'da 206 farklı orijinli Borago officinalis L. çeşit ve popülasyonları ile yürüttükleri bir çalışmada 1000 tane ağırlı̆ı̆ını ortalama $14.1 \mathrm{~g}$ ile $23.1 \mathrm{~g}$ arasında elde etmişlerdir. Berti ve ark. (2010) ise yaptıkları araştırmada 1000 dane ağırlığını farklı azot uygulamalarına göre $12.3 \mathrm{~g}$ ile 16.4 aralığında belirlemişler, en yüksek değeri hiç azot uygulanmayan parselden elde etmişlerdir. Bulmuş olduğumuz değerler her iki çalışmada da belirlenen sınırlar içerisinde yer almaktadır.

Çizelge 1'de verilen dal sayıları incelendiğinde sıra arası mesafe arttıkça dal sayısında da artış olmuş ancak bu artış her iki yetiştirme yılında da istatistiksel olarak önemsiz bulunmuştur. İstatistiksel olarak önemli olmamakla beraber ilk ve ikinci yıl en yüksek dal sayıları $50 \mathrm{~cm}$ ve $60 \mathrm{~cm}$ sıra arası mesafelerinde sırasıyla 7.46 adet/bitki, 7.16 adet bitki ve 8.10 adet/bitki, 7.76 adet/bitki olarak saptanmıştır. Kolza çeşitleri ile yürütülen bir çalışmada da iki yılın ortalaması olarak en yüksek ana sapa bağlı yan dal sayıları $50 \mathrm{~cm}$ mesafede elde edilmiş, bunu $40 \mathrm{~cm}$ ve $30 \mathrm{~cm}$ izlemiştir (Öztürk, 2000). Şekeroğlu (2003) Çukurova Bölgesi kıraç ve taban arazi koşullarında bitki sıkığı ve azotlu gübre uygulamalarının Oenothera biennis L. üzerine etkilerini araştırdıkları çalışmasında, taban arazide en fazla dal sayısını en geniş sıra arası mesafesinde belirlemiştir. $\mathrm{Bu}$ sonuçlar ile bizim bulgularımız uyum içerisindedir. Farklı organik, azotlu ve fosforlu gübrelerin Borago officinalis bitkisinin büyüme ve verimi üzerine etkilerini inceledikleri çalışmada Hendawy ve El-Gengaihi (2010) dal sayısını 13.30 adet/bitki-18.70 adet/ bitki olarak elde etmişlerdir. Araştırmada belirlediğimiz verilerin bu değerlerin altında olduğu izlenmiştir.

Salkım sayısı bakımından ortalamalara bakıldığında, ilk yıl 27.40 adet/bitki-41.86 adet /bitki, ikinci yıl 31.50 adet/bitki-33.85 adet/bitki aralığında belirlenmiştir (Çizelge 1). Yıllar ortalaması değerleri incelendiğinde, sıra arası mesafe genişledikçe salkım sayısının da arttığı gözlenmiştir. Deneme yıllarında en yüksek salkım sayısına $60 \mathrm{~cm}$ sıra arası mesafede ulaşılmışıı. Her iki yılda da sıra arası mesafeleri arasındaki farklılıklar istatistiksel olarak önemsiz olmuştur. Illk yıla ilişkin sıra arası mesafesi değerleri arasındaki geniş sayısal farklılığa karşın varyans analizinde hata kareler ortalamasının nispeten büyük oluşu olasilıkla istatistiksel önemsizliğe yol açmıştır. Bu bitki ile ilgili olarak daha önce salkım sayılarının saptandığı bir çalışmaya da rastlanmamıştır.

Tane verimi açısından Çizelge 1 incelendiğinde, iki yetiştirme döneminin her birinden elde edilen değerlerde istatistiksel olarak \%1 düzeyinde farklılık gözlenmiştir. İlk yıl en düşük değer $44.38 \mathrm{~kg} / \mathrm{da}$, en yüksek değer 76.39 kg/da; ikinci yılda ise sırasıyla; 41.67 $\mathrm{kg} / \mathrm{da}$ ve $79.72 \mathrm{~kg} / \mathrm{da}$ olarak kaydedilmiştir. Her iki yılda da $50 \mathrm{~cm}$ ve $60 \mathrm{~cm}$ sıra arası mesafelerinden elde edilen değerler istatistiksel olarak ilk grupta yer almıştır. Çalışmamızda sıra arası mesafe arttıkça tane veriminde de artış olduğu görülmüştür. Yaptığımız incelemelerde Borago officinalis bitkisi üzerinde daha önce sıra arası mesafe ile ilgili yapılmış çalışmaya rastlanmamıştır. Yetiştirme tekniğine yönelik diğer çalışmalar göz önüne alındığında, Hendawy ve El-Gengaihi (2010) farklı azot ve fosfor uygulamalarında dane verimini $75.7 \mathrm{~kg} / \mathrm{da}$ ile $142.0 \mathrm{~kg} / \mathrm{da}$ arasında belirlemişler, en düşük değeri de kontrol parselinden elde etmişlerdir. El Hafid ve ark. (2002) farklı ekim tarihleri ve azotlu gübre uygulamalarının tohum verimine etkisini araştırdıkları çalışmalarında, en yüksek dane verimini erken ekim ve erken hasat döneminde ilk yıl 68.0-79.4 kg/da, ikinci yıl 38.9-45.8 kg/da olarak belirlemişlerdir. Ekim zamanı geciktikçe verimin azaldığını belirten araştıııılar geç hasat döneminde en düşük dane verim değerlerini elde etmişlerdir. Çalışmamızda elde ettiğimiz verim değerleri Hendawy ve El-Gengaihi (2010)'in bildirdikleri verilerden düşük, El Hafid ve ark. (2002)'nın tespit ettikleri değerlere yakın bulunmuştur. Yürüttüğümüz denemede de bitkide tohum dökme olayının çok fazla olması nedeniyle hasadın mümkün olduğunca erken yapılması gerektiği ortaya çıkmıştır.

Çizelge 2 incelendiğinde, Borago officinalis L.'de sabit yağ oranının denemenin ilk yılında \%29.96 ile 
34.04, ikinci yıl da ise \%30.13 ile 33.67 arasında değiştiği ve iki yılın ortalaması \%30.05 ile 33.86 aralığında yer aldığı görülmektedir. Her iki yılda da en yüksek sabit yağ oranı en dar sıra arası mesafesi $(30 \mathrm{~cm})$ uygulamasında, en düşük sabit yağ oranı ise sıra arası mesafesi $60 \mathrm{~cm}$ 'ye ulaştığında elde edilmiştir. Ancak özellikle ikinci yılda 60 $\mathrm{cm}$ sıra arası mesafesi dışındakilere ilişkin değerlerin birbirine çok yakın olduğu gözlenmiştir. Denemede yağ oranı açısından $60 \mathrm{~cm}$ sıra arası mesafesinde elde edilen değerlerin diğer mesafelerdekilerden belirgin olarak farklı olduğu görülmüştür. De Haro ve ark., (2002) İspanya'da farklı orijinli Borago officinalis L. popülasyonları ile yürüttükleri bir çalışmada, sabit yağ oranını \%29.6-35.8 olarak tespit etmişlerdir. Hendawy ve El Gengaihi (2004) farklı gübre uygulamalarında yağ oranını \%21.0-42.80 aralığında bildirmişlerdir. Özcan (2008) Türkiye florasından topladığı Borago officinalis L. bitkisinde yağ oranını \%31 olarak belirlemiştir. Morteza ve ark. (2015) İran (Shahriyar ve Garmsar)'da yaptıkları bir çalışmada Borago officinalis'de yağ oranını \%31.46-33.7 olarak elde etmişlerdir. Çalışmamızda belirlediğimiz sabit yağ oranları da sözü edilen araştırmalarda belirtilen değerler içinde yer almaktadır.

Yapılan literatür incelemesinde daha önce Borago officinalis bitkisi üzerinde sıklıkla ilgili yürütülmüş bir çalışmaya rastlanmamıştır. Kolzada yapılan bir çalışmada (Kondra, 1975), genellikle en dar sıra arasında en yüksek yağ oranının elde edildiği bildirilmiştir. Diğer bazı araştırmalarda da (Ali ve ark., 1996; Kumar ve ark., 1996) yağ oranının sıra arası mesafesinin artması ile azaldığı ifade edilmiştir. Bu sonuçlar bizim bulgularımız ile uyum içerisindedir. Yaptığımız çalışmada her iki yılda da en dar sıra arası mesafede $(30 \mathrm{~cm})$ en yüksek yağ oranı elde edildiği, sıra arası mesafesi $60 \mathrm{~cm}$ 'ye çıktığında ise oranda her iki yılda da bir azalma görüldüğü saptanmıştır.

Çizelge 2. Borago officinalis L.'de Farklı Sıra Arası Mesafelerinin Sabit Yağ Oranı ve Yağ Asitleri Bileşimine Etkileri (\%)

Table 2. The Effect of Different Row Spacings on Oil Content and Composition in Borago officinalis L. (\%)

\begin{tabular}{|c|c|c|c|c|c|c|c|c|}
\hline \multicolumn{9}{|c|}{ 2014-2015 } \\
\hline $\begin{array}{c}\text { Sıra Arası } \\
\text { Mesafe }(\mathrm{cm})\end{array}$ & $\begin{array}{c}\text { Sabit Yağ } \\
\text { Yüzdesi (\%) }\end{array}$ & $\begin{array}{c}\text { Palmitik } \\
\text { Asit } \\
(\mathrm{C} 16: 0)\end{array}$ & $\begin{array}{c}\text { Stearik } \\
\text { Asit } \\
(\mathrm{C} 18: 0)\end{array}$ & $\begin{array}{l}\text { Oleik Asit } \\
(C 18: 1)\end{array}$ & $\begin{array}{l}\text { Linoleik } \\
\text { Asit } \\
\text { (C18:2) }\end{array}$ & $\begin{array}{l}\text { Y- Linolenik } \\
\text { Asit (C18:3) }\end{array}$ & $\begin{array}{l}\text { Eikosenoik } \\
\text { Asit (C20:1) }\end{array}$ & $\begin{array}{l}\text { Erüsik Asit } \\
\text { (C22:1) }\end{array}$ \\
\hline 30 & 34.04 & 13.42 & 3.86 & 20.06 & 36.56 & 18.62 & 4.10 & 2.65 \\
\hline 40 & 33.31 & 13.42 & 4.15 & 20.34 & 36.64 & 18.17 & 4.24 & 2.48 \\
\hline 50 & 33.45 & 13.26 & 3.84 & 20.64 & 37.21 & 18.14 & 4.09 & 2.28 \\
\hline 60 & 29.96 & 13.20 & 3.77 & 20.59 & 36.94 & 18.25 & 4.15 & 2.48 \\
\hline Genel Ort & 32.69 & 13.33 & 3.91 & 20.41 & 36.84 & 18.30 & 4.15 & 2.47 \\
\hline \multicolumn{9}{|c|}{ 2015-2016 } \\
\hline $\begin{array}{c}\text { Sıra Arası } \\
\text { Mesafe }(\mathrm{cm})\end{array}$ & $\begin{array}{c}\text { Sabit Yağ } \\
\text { Yüzdesi (\%) }\end{array}$ & $\begin{array}{c}\text { Palmitik } \\
\text { Asit } \\
(\mathrm{C} 16: 0)\end{array}$ & $\begin{array}{c}\text { Stearik } \\
\text { Asit } \\
(\mathrm{C} 18: 0)\end{array}$ & $\begin{array}{l}\text { Oleik Asit } \\
(\text { C18:1) }\end{array}$ & $\begin{array}{l}\text { Linoleik } \\
\text { Asit } \\
\text { (C18:2) }\end{array}$ & $\begin{array}{l}\text { Y- Linolenik } \\
\text { Asit (C18:3) }\end{array}$ & $\begin{array}{l}\text { Eikosenoik } \\
\text { Asit (C20:1) }\end{array}$ & $\begin{array}{l}\text { Erüsik Asit } \\
\text { (C22:1) }\end{array}$ \\
\hline 30 & 33.67 & 13.20 & 3.86 & 20.45 & 36.39 & 18.80 & 4.16 & 2.51 \\
\hline 40 & 33.18 & 13.21 & 3.99 & 20.41 & 36.16 & 18.58 & 4.26 & 2.71 \\
\hline 50 & 33.63 & 12.95 & 3.71 & 20.50 & 37.86 & 18.61 & 4.09 & 2.45 \\
\hline 60 & 30.13 & 13.00 & 3.96 & 20.88 & 36.70 & 18.14 & 4.04 & 2.59 \\
\hline Genel Ort & 32.65 & 13.09 & 3.88 & 20.56 & 36.78 & 18.53 & 4.14 & 2.57 \\
\hline \multicolumn{9}{|c|}{ Yıllar Ortalaması } \\
\hline $\begin{array}{c}\text { Sıra Arası } \\
\text { Mesafe }(\mathrm{cm})\end{array}$ & $\begin{array}{c}\text { Sabit Yağ } \\
\text { Yüzdesi (\%) }\end{array}$ & $\begin{array}{c}\text { Palmitik } \\
\text { Asit } \\
(\mathrm{C} 16: 0)\end{array}$ & $\begin{array}{c}\text { Stearik } \\
\text { Asit } \\
(\mathrm{C} 18: 0)\end{array}$ & $\begin{array}{l}\text { Oleik Asit } \\
(C 18: 1)\end{array}$ & $\begin{array}{l}\text { Linoleik } \\
\text { Asit } \\
(\mathrm{C} 18: 2)\end{array}$ & $\begin{array}{l}\text { Y- Linolenik } \\
\text { Asit (C18:3) }\end{array}$ & $\begin{array}{l}\text { Eikosenoik } \\
\text { Asit (C20:1) }\end{array}$ & $\begin{array}{l}\text { Erüsik Asit } \\
\text { (C22:1) }\end{array}$ \\
\hline 30 & 33.86 & 13.31 & 3.86 & 20.26 & 36.48 & 18.71 & 4.13 & 2.58 \\
\hline 40 & 33.25 & 13.31 & 4.07 & 20.37 & 36.40 & 18.37 & 4.25 & 2.60 \\
\hline 50 & 33.54 & 13.11 & 3.78 & 20.57 & 37.54 & 18.37 & 4.09 & 2.36 \\
\hline 60 & 30.05 & 13.10 & 3.87 & 20.74 & 36.82 & 18.20 & 4.09 & 2.53 \\
\hline Genel Ort & 32.68 & 13.21 & 3.90 & 20.49 & 36.81 & 18.41 & 4.14 & 2.52 \\
\hline
\end{tabular}

Yağ asitleri bileşimleri açısından oleik asit, linoleik asit ve $Y$ - linolenik asit Borago officinalis tohumlarında bulunan üç ana bileşen oldukları bilinmektedir. Denemenin ilk yılında oleik asidin genel ortalaması \% 20.41, linoleik asit ve $Y$ - linolenik asitlerin oranları ise sırasıyla \%36.84 ve 18.30 olarak belirlenmiştir. Denemenin ikinci yılında ise oleik asit oranı \%20.56, linoleik asit oranı \%36.78 ve $Y$ - linolenik asit oranı
\%18.53 olarak bulunmuştur. Deneme faktörlerine ilişkin yağ asitlerinin oranları incelendiğinde, palmitik asidin en yüksek orana denemenin ilk ve ikinci yılında da 30 ve $40 \mathrm{~cm}$ sıra arası mesafelerinde ulaştığı, en düşük oranların ise denemenin ilk yılında $60 \mathrm{~cm}$, ikinci yılında ise $50 \mathrm{~cm}$ sıra arası mesafelerinde elde edildiği ifade edilebilir. Stearik asidin en yüksek oranı denemenin hem ilk ve hem de ikinci yılında $40 \mathrm{~cm}$ sıra arası 
mesafesinde, en düşük oranı denemenin ilk yılında 60 $\mathrm{cm}$ ve ikinci yılında $50 \mathrm{~cm}$ sıra arası mesafelerinde saptanmıştır. İki yılın ortalaması olarak ise en yüksek ve en düşük oranlar sırasıyla 40 ve $50 \mathrm{~cm}$ sıra arası mesafelerinde elde edilmiştir (Çizelge 2).

Borago officinalis'in sabit yağında ana bileşenlerden biri olarak bilinen oleik asit en yüksek oranlara denemenin ilk yılında $50 \mathrm{~cm}$, denemenin ikinci yılında ise $60 \mathrm{~cm}$ sıra arası mesafelerinde ulaşmıştır. Yıllar ortalamasında en yüksek ve en düşük oleik asit oranlarının 60 ve $30 \mathrm{~cm}$ sıra arası mesafelerinde olduğu belirlenmiştir. Borago officinalis sabit yağının bir diğer ana bileşeni olan linoleik asidin en yüksek oranı denemenin birinci ve ikinci yıllarında $50 \mathrm{~cm}$ sıra arası mesafesinde belirlenmiş, en düşük oranları ise denemenin ilk yılında $30 \mathrm{~cm}$ ve ikinci yılında ise $40 \mathrm{~cm}$ sıra arası mesafelerinde elde edilmiştir. Yıllar ortalamasında ise 40 ve $50 \mathrm{~cm}$ sıra arası mesafelerinin en düşük ve en yüksek oranları verdiği izlenmektedir. Borago officinalis sabit yağında en önemli bileşen olarak kabul edilen $Y$ - linolenik asitin oranı ise denemenin ilk yılında en yüksek oranı $30 \mathrm{~cm}$, en düşük oranı $50 \mathrm{~cm}$ sıra arası mesafesinde elde edilirken, denemenin ikinci yılında ise en yüksek ve en düşük oranları sırasıyla 30 ve $60 \mathrm{~cm}$ sıra arası mesafelerinde saptanmıştır. İki yılın ortalamasında ise en yüksek oranın $30 \mathrm{~cm}$, en düşük oranın ise $60 \mathrm{~cm}$ sıra arası mesafelerinde olduğu belirlenmiştir Eikosenoik asit oranlarına bakıldığında ise denemenin ilk yılında en yüksek orana $40 \mathrm{~cm}$ sıra arası mesafesinde ulaşmış, en düşük oranı ise $50 \mathrm{~cm}$ sıra arası mesafesinde belirlenmiş̧ir. Denemenin ikinci yılında da en yüksek oran $40 \mathrm{~cm}$ sıra arası mesafesinde, en düşük oran 60 $\mathrm{cm}$ sıra arası mesafesinde bulunmuştur. Yıllar birleştirildiğinde en yüksek oranı $40 \mathrm{~cm}$, en düşük oranlar 50 ve $60 \mathrm{~cm}$ sıra arası mesafelerinde belirlenmiştir. Erüsik asit oranına bakıldığında, en yüksek oran ilk yılda $30 \mathrm{~cm}$, ikinci yılda $40 \mathrm{~cm}$ sıra arası mesafelerinde elde edilirken, denemenin her iki yılında da en düşük erüsik asit oranı $50 \mathrm{~cm}$ sıra arası mesafesinde saptanmıştır. Deneme yılları ortalamasında en yüksek ve en düşük erüsik asit oranları sırasıyla 40 ve $50 \mathrm{~cm}$ sıra arası mesafelerinde kaydedilmiştir (Çizelge 2).

Yapılan kaynak taramasında sıra arası mesafelerinin yağ bileşimine etkileri ile ilgili bir çalışmaya rastlanmamıştır. Borago officinalis L. üzerinde yürütülen diğer çalışmalar incelendiğinde, De Haro ve ark. (2002) üç farklı kökenli 206 adet Borago officinalis L. popülasyonu ile yaptıkları denemede genel ortalama olarak palmitik asit oranını $\% 10.1-11.1$, stearik asit oranını \%3.4-4.64, oleik asit oranını \%15.5-27.6, linoleik asit oranını \%32.7-38.8, Ylinolenik asit oranını \%18.9-25.2, eikosenoik asit oranını \%3.6-5.6 ve erüsik asit oranını \%1.6-3.7 olarak elde etmişlerdir. Özcan (2008) Türkiye florasından topladığı Boraginaceae familyasına dahil 24 takson ile yürüttüğü çalışmada, Borago officinalis L. bitkisi yağında linoleik asit oranını \%35.21, Y- linolenik asit oranını ise \%16.87 olarak tespit etmiştir. Berti ve ark. (2010) yapmış oldukları araştırmada, palmitik asit oranını \%9.9-10.7, stearik asit oranını \%1.1-4.4, oleik asit oranını \%35.9-37.6, linoleik asit oranını \%37.2-37.6 ve $Y$ - linolenik asit oranını \%20.5-22.1 olarak belirlemişlerdir. Araştırmamızda sabit yağı oluşturan bileşenlerin değerleri diğer çalışmalarda elde edilen bulgularla kıyaslandığında, De Haro ve ark. (2002) ve Berti ve ark. (2010)'nın bildirdiği palmitik asit oranlarından yüksek, stearik asit oranlarına yakın, oleik asit ve $Y$ - linolenik asit oranlarından düşük, linoleik oranlarına ise yakın bulunmuştur. Özcan (2008)'nın bildirmiş olduğu linoleik asit ve $Y$ - linolenik asit değerleri bizim sonuçlarımız ile uyum içerisindedir.

\section{SONUÇ}

$\mathrm{Bu}$ araştırmada iki yıl boyunca farklı sıra arası mesafelerinin Borago officinalis L. (Hodan) bitkisinin bazı agronomik özellikleri ile sabit yağ oranı ve bileşimine etkisi belirlenmeye çalışılmıştır.

Menemen ekolojik koşullarında yürütülen çalışmada, sıra arası mesafe arttıkça 1000 tane ağırlığı dışındaki karakterlerde (bitki boyu, dal sayısı, salkım sayısı ve tane verimi) değişen düzeylerde artış gözlenmiştir. Ancak bu artışlar sadece bitki boyu ve tane veriminde istatistiksel olarak anlamlı farklılıklar oluşturmuştur.

Araştırma sonuçları sabit yağ oranının ise sıra arası mesafe daraldıkça artıı̆ını ve en geniş sıra arası mesafede $(60 \mathrm{~cm})$ iki yıl ortalaması olarak en düşük değerin (\%30.05) kaydedildiğini göstermiştir. Çalışmada sabit yağ bileşiminde linoleik asit (C18:2), oleik asit (C18:1) ve $Y$ - linolenik asit (C18:3)'in üç önemli bileşen olduğu tespit edilmiştir. Literatürde $Y$ - linolenik asit (GLA) kaynağı olarak gösterilen üç bitkiden (hodan (Borago officinalis L.), gece sefası (Oenothera biennis L.) ve frenk üzümü (Ribes nigrum L.)) biri olan Borago officinalis L. (hodan)'de Y- linolenik asit (GLA) oranı ise sıra arası mesafelerine göre bir farklılık göstermemiştir.

Sonuçta, Borago officinalis L. bitkisinde kabul edilebilir tane verimi ile birlikte yüksek düzeyde yağ içeriği elde edilebilmesi bakımından $50 \mathrm{~cm}$ sıra arası mesafesinin uygulanması gerektiğini söylemek mümkündür.

\section{TEŞEKKÜR}

$\mathrm{Bu}$ çalışmada özellikle sabit yağ bileşenlerinin belirlenmesinde desteğini esirgemeyen Sayın Prof. Dr. Fatih Şen'e teşekkürlerimizi sunarız. 


\section{KAYNAKLAR}

Açıkgöz, N., İlker, E. Ve Gökçöl, A., 2004. Biyolojik Araştırmaların Bilgisayarda Değerlendirmeleri. Ege Üniversitesi Tohum Teknolojisi Uygulama ve Araştırma Merkezi Yayınları, No: 2, İzmir, $236 \mathrm{~s}$.

Ali, M.H., Zaman, S.M.H. Hossain S.M.A., 1996. Variation in Yield, Oil and Protein Content of Rapeseed (Brassica campestris) in Relation to Levels of Nitrogen, Sulphur and Plant Density. Indian Journal of Agronomy. 41(2): 290-295.

Baytop, T., 1999. Türkiye'de Bitkiler ile Tedavi (Geçmişte ve Bugün). Nobel Tıp Kitabevleri, Ltd. Şti. S. 480.

Berti, M. T., Fischer, S. U., Wilckens, R. L., Hevia M. F., Johnson, B. L., 2010. Borage (Borago officinalis L.) Response to N, P, K, and Fertilization in South Central Chile. Chilean Journal of Agricultural Research 70 (2): 228-236.

Bone, K. and Mills, S. (Auth), 2013. Principles and Practive of Phytotherapy. Modern Herbal Medicine, Churchill Livingstone. $1065 \mathrm{pp}$.

Cergel, S., Bayram, E., Honermeier, B., 2006. Untersuchung zur Cadmiumaufnahme von Borretsch (Borago officinalis L.) in Abhangigkeit von der Herkunft. Deutsch-Türkısche Agrarforschung 8. Symposium 04-Oktober-08 Oktober 2005, Cuvillier Verlag 463-468.

De Haro, A., Dominguez, V., Mercedes Del R., 2002. Variability in the Content of Gamma- Linolenic Acid and Other Fatty Acids of the Seed Oil of Germplasm of Wild and Cultivated Borage (Borago officinalis L.). Journal of Herbs, Spices and Medicinal Plants. The Haworth Herbal Press, 297-304.

El Hafid R., Blade S.F., Hoyano Y. 2002. Seeding Date and Nitrogen Fertilization Effects on the Performance of Borage (Borago officinalis L.). Industrial Crops and Products. 16: 193 . 199.

Gunstone FD., 1998. Movements Towards Tailor-Made Fats. Prog Lipid Res. 1998; 37:277-305.

Hendawy, S.F., El-Gengaihi, 2010. Comparative Responses of Borago officinalis and Echium vulgare to Different Nitrogen and Phosphorus. Journal of Herbs, Spices-Medicinal Plants, $16: 12-23$
IUPAC, 1979. Standard Methods for the Analysis of Oils, Fats and Derivatives. Pergamon Press, Oxford: International Union of Pure and Applied Chemistry. 151 pp.

Kumar, R., Negi, P.S., Singh, C.M., Mankotia, B.S. 1996. Performance of Gobhi Sarson (Brassica napus subsp. oleifera var. napus) under Various Planting Dates and Row Spacing in Himachal Pradesh. Indian Jounal of Agronomy. 41 (1):98-100.

Kondra, Z.P., 1975. Effects of Row Spacing and Seeding Rate on Rapeseed. Canadian Journal of Plant Science. 55: 339-341.

Medrano, A., Masoud, T.A., Martinez, M.C., 1992. Mineral and Proximate Composition of Borage. J. Food Comp. Anal. 5 (4), 313-318.

Morteza, E., Akbari, G.A., Moaveni, P., Alahdadi, I., Bihamta M.R., Hasanloo, T., Joorabloo, A., 2015. Compositions of the Seed Oil of the Borago officinalis from Iran. Natural Product Research, Vol. 29, No. 7, 663-666.

Özcan, T., 2008. Analysis of the Total Oil and Fatty Acid Composition of Seeds of Some Boraginaceae Taxa from Turkey. Plant Syst. Evol. (2008) 274; 143-153.

Öztürk, Ö., 2000. Bazı Kışlık Kolza Çeşitlerinde Farklı Ekim Zamanı ve Sira Arası Uygulamalarının Verim, Verim unsurları ve Kalite Üzerine Etkileri (Doktora Tezi). Selçuk Üniversitesi, Fen Bilimleri Enstitüsü. S. 147, Konya.

Samani, M.A., Bahmani, M., Kopaci, M.R., 2014. The Chemical Composition, Botanical Characteristic and Biological Activities of Borago officinalis: a review. Asian Pacific Journal of Tropical Medicine, 2014;7(Suppl 1): S22-28.

Şekeroğlu, N., 2003. Çukurova Bölgesi Kıraç ve Taban Arazi Koşullarında Bitki Sıklığı ve Azotlu Gübre Uygulamalarının Oenothera biennis L. Bitkisinin Verim ve Kalitesine Etkisi (Doktora Tezi). Çukurova Üniversitesi Fen Bilimleri Enstitüsü, Adana.

Zeybek, N., Zeybek, U., 1994. Farmasötik Botanik, Kapalı Tohumlu Bitkiler (Angiospermae) Sistematiği ve Önemli Maddeleri. Ege Üniversitesi Eczacılık Fakültesi Yayınları No: 2., S. 436, Bornovaİzmir. 